\title{
Consolidation Potential of Rural Residential Areas Based on the Village Classification
}

\author{
Wei Li, Xicun Zhu*, Jingwen Yang, Zhongyu Tian, Xueyuan Bai, Li Sun, Xiaoying Tang \\ National Engineering Laboratory for Efficient Utilization of Soil and Fertilizer Resources, College of Resources \\ and Environment, Shandong Agricultural University, Taian, China \\ Email: ^t110e51@163.com
}

How to cite this paper: Li, W., Zhu, X.C., Yang, J.W., Tian, Z.Y., Bai, X.Y., Sun, L. and Tang, X.Y. (2021) Consolidation Potential of Rural Residential Areas Based on the Village Classification. Journal of Agricultural Chemistry and Environment, 10, 289-304. https://doi.org/10.4236/jacen.2021.103018

Received: May 7, 2021

Accepted: June 25, 2021

Published: June 28, 2021

Copyright () 2021 by author(s) and Scientific Research Publishing Inc. This work is licensed under the Creative Commons Attribution International License (CC BY 4.0).

http://creativecommons.org/licenses/by/4.0/

\section{(c) (i) Open Access}

\begin{abstract}
From the perspective of village classification, a set of methods for accurately measuring the potential of rural settlement consolidation are proposed. Taking Feicheng in Shandong Province as the research area, combined with the corresponding planning, a classification and evaluation system for rural residential areas was constructed to classify rural residential areas from the four levels of natural resources, economy and society, supporting facilities and livability. The theoretical and practical potential of one type of rural settlements (relocating and merger village) is mainly calculated, and the potential scale, potential level and potential spatial distribution of different regions are analyzed. (Level and spatial distribution are analyzed. The results showed that the 621 rural settlements can be divided into five types: 148 urban-rural integration villages (URIV), 41 historical and cultural villages (HCV), 56 cluster developing villages (CDV), 155 keeping and limiting villages (KLV) and 221 relocating and merger villages (RMV). According to calculations, the theoretical potential of relocating and merger village areas was $1971.47 \mathrm{hm}^{2}$, accounting for $19.52 \%$ of the total scale of Feicheng residential areas; the comprehensive correction coefficient of each region was $0.48-0.70$, and the revised actual potential is $1082.68 \mathrm{hm}^{2}$, accounting for the theoretical potential $54.92 \%$ of the total. There were large spatial differences in the scale of potential in different regions. In general, the theoretical and practical potential of the central and southern regions was higher than that of the northern regions.
\end{abstract}

\section{Keywords}

Rural Residential Land, Classification of Village, Consolidation Potential, Village Classification

\section{Introduction}

Land resources are important resources necessary for human social survival and 
development. In recent years, my country's urbanization process has accelerated, and large numbers of people engaged in agriculture have moved out of rural areas, causing air-to-hearting, one-family multi-homes, restricted space, etc. [1]. These unreasonable landing phenomena cause serious land waste, and the use of agricultural modernization and ecological protection has gradually increased, so that rural areas have more contradictions in land use. Therefore, scientifically reasonably carry out rural land finishing, improving land-use efficiency, and thereby achieving land savings.

Due to the factors such as developing status, custom history and resource endowment, my country's different rural areas, the development law and evolution trend of rural residential points have shown a large difference [2]. Therefore, the type of scientific division of rural residential points is the premise of carrying out the finishing of rural residential points. In terms of rural residential classification, domestic and foreign scholars have focused on suitable aspects of suitability evaluation, spatial evolution characteristics and spatial layout optimization [3]-[10]. Generally based on geographic information system technology, combined with geographical statistical analysis methods, weighted voronoi diagrams, landscape index and minimum cumulative resistance model (MCR), etc., comprehensive considering natural, humanities and ecology, etc., for rural residents Spatial layout optimization and classification [11]-[16]. In terms of rural residential point, many scholars have also conducted the following research, 1) Theoretical potential measurement: mainly, some of the construction standards [17], household construction land standard method [18], idle rate method [19], volume ratio [20] and urban system planning methods [21]. According to the current area of rural settlements and the corresponding national standards, the area difference is a theoretical potential. 2) Realistic potential measurement: In order to make more practical operability, scholars generally choose factors such as natural, economic, social, ecological, and planning orientation, and build multi-level step-by-step correction model, and conversion to partial potential value The limit factors are quantified [22]-[29]. Different comprehensive evaluation systems are closely related to the local characteristics and general. In addition, some researchers introduce farmers' wishes [30] into the correction model, suitable for small and medium-size regions. There are also scholars to use GIS to build land to organize the database to master the potential of rural residential points [31]. However, in the actual development of rural residential points, there is a big gap between the potential and the actual situation of the measurement. It is mainly due to different types of rural residents, and its organizational potential is different. Such as agglomeration development and characteristic protection rural residential points are subjects of key development and protection, and the potential released after the finishing is extremely limited, and sometimes it is necessary to meet the development needs, and even need further expand the land. Relocating and merger village is a type of short board in partial levels such as production and development, or a type of demolition and demolition, which requires overall 
relocation and demolition, can be based on national standards, scientific layout and planning new residential points. Construction to achieve the purpose of saving the land, release the potential. Most of the previous researches did not consider the effects of different types of rural residential points on the potential. Because, the calculated potential errors were large and the actual needs cannot be met, there is an urgent need to carry out the consolidation of rural residential areas to efficiently and intensively use land

In order to eliminate the impact of different types of rural residential points on the potential of the calculation, this paper put forward a set of accurately calculating the ranking of rural residential points, namely the corresponding plan, first construct a rural residential classification evaluation system, for rural residents Classification, re-use the real potential comprehensive evaluation model, focus on the reality of relocating and merger village, with a view to accurately calculate the potential of regional rural residential points, and provide data support for the preparation of county rural planning and actual development of rural residential points.

\section{Materials and Methods}

\subsection{Study Area}

Feicheng (Figure 1) is located in the middle of Shandong Province and borders
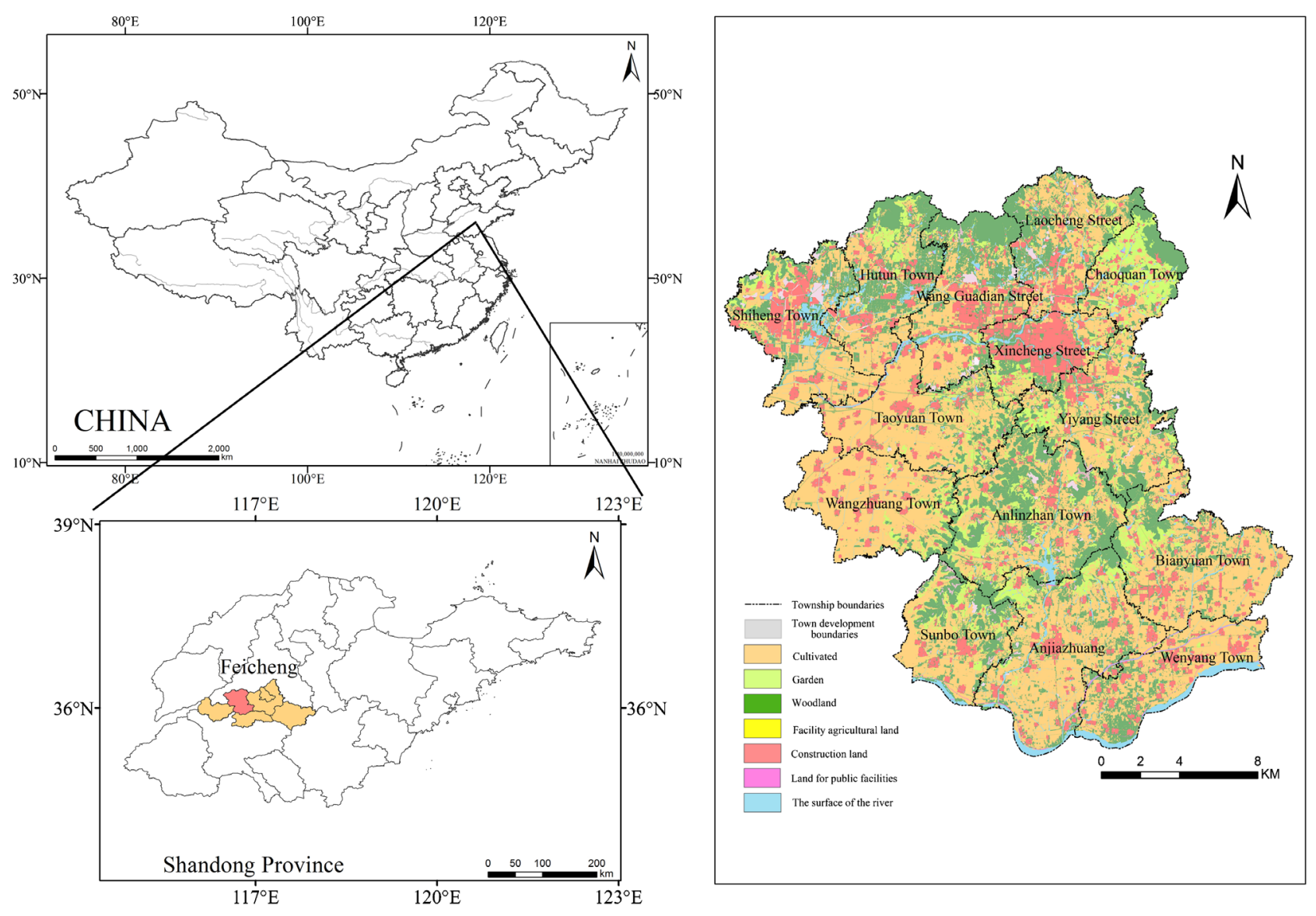

Figure 1. Map of land use in Feicheng. 
Mount Tai in the east. There are 14 townships under its jurisdiction. It has a population of 502,000 in urban areas and 490,000 in rural areas, with a total area of $127,700 \mathrm{hm}^{2}$. At present, the per capita construction land area in Feicheng rural areas is $129.25 \mathrm{~m}^{2} /$ person, which is 1.29 times the highest standard in Shandong Province. The lack of scientific planning and "extensive" management in the construction of rural residential areas has caused a serious waste of land resources. Therefore, there is an urgent need to carry out the consolidation of rural residential areas to efficiently and intensively use land.

The data for the research on the status, location, and land use of rural residential areas and various infrastructures are mainly derived from the third national land and resources survey database; economic conditions and social environment data are derived from the "2018 Taian Statistical Yearbook".

\subsection{Combining Planning to Classify the Types of Rural Residential Areas}

The rural residential areas in the suburbs of cities and towns and county towns and towns have gradually turned to urbanization or have the conditions for transformation to urbanization. The evolution direction is defined as the integration of urban and rural areas; Fei cities have features, historical and cultural landscapes, and special protection values. Rural residential areas are retained and listed as characteristic protected rural residential areas.

\subsubsection{Classification and Evaluation Index System of Rural Residential Areas}

In this study, 12 factors were selected from the four levels of resource endowment, social economy, supporting facilities and livability, as the evaluation indicators of the general rural settlement classification evaluation system, as shown in Table 1 .

\subsubsection{Index Weight Calculation and Classification}

The coefficient of variation method is a widely used objective weighting method in the evaluation of relevant land [32].

1) Calculate the coefficient of variation $V_{i}$ :

$$
V_{i}=\frac{\sigma_{i}}{\bar{x}_{i}}(i=1,2, \cdots, n)
$$

2) Calculate the weight of each indicator $W_{i}$ :

$$
W_{i}=\frac{V_{i}}{\sum_{i=1}^{n} V_{i}}(i=1,2, \cdots, n)
$$

3) Range standardization treatment:

$$
\begin{gathered}
\text { Positive index : } X_{n i}=\frac{X_{i j}-X_{i \min }}{X_{i \max }-X_{i j}} \\
\text { Negative index : } X_{n i}=\frac{X_{i \max }-X_{i j}}{X_{i j}-X_{i \min }}
\end{gathered}
$$


Table 1. Classification and evaluation index system of rural residential areas.

\begin{tabular}{|c|c|c|c|c|c|}
\hline $\begin{array}{l}\text { Criterion } \\
\text { level }\end{array}$ & Indicator level & Index description & $\begin{array}{l}\text { Indicator } \\
\text { attributes }\end{array}$ & Weight & $\begin{array}{l}\text { Coefficient } \\
\text { of Variation }\end{array}$ \\
\hline & Residential area size & Rural settlement scale $/ \mathrm{km}^{2}$ & + & 0.1105 & 0.7395 \\
\hline \multirow{3}{*}{$\begin{array}{l}\text { Natural } \\
\text { resources }\end{array}$} & Cultivated land ratio & Cultivated land area of residential area/area of residential area & + & 0.0696 & 0.4654 \\
\hline & $\begin{array}{l}\text { Proportion of } \\
\text { agricultural facilities }\end{array}$ & Area of agricultural facilities in residential area/area of residential area & + & 0.0840 & 0.5618 \\
\hline & Revenue & Fiscal revenue of local township governments & + & 0.1387 & 0.9281 \\
\hline \multirow[t]{3}{*}{$\begin{array}{l}\text { Economy } \\
\text { and society }\end{array}$} & $\begin{array}{l}\text { Intensity of } \\
\text { settlements }\end{array}$ & Rural settlement area/number of patches & + & 0.0948 & 0.6342 \\
\hline & traffic condition & The average time from each road node to other nodes $/ \mathrm{min}$ & - & 0.0666 & 0.4453 \\
\hline & $\begin{array}{l}\text { Commercial Service } \\
\text { Facilities }\end{array}$ & $\begin{array}{l}\text { The shortest Euclidean distance between residential areas and } \\
\text { commercial service facilities } / \mathrm{m}\end{array}$ & - & 0.0891 & 0.5964 \\
\hline \multirow[t]{3}{*}{$\begin{array}{l}\text { Supporting } \\
\text { facilities }\end{array}$} & $\begin{array}{l}\text { Medical education } \\
\text { facilities }\end{array}$ & $\begin{array}{l}\text { The shortest Euclidean distance between the residential area and the } \\
\text { medical education facility/m }\end{array}$ & - & 0.1012 & 0.6771 \\
\hline & public facility & $\begin{array}{l}\text { The shortest Euclidean distance between residential areas and public } \\
\text { service facilities } / \mathrm{m}\end{array}$ & - & 0.0872 & 0.5831 \\
\hline & Geological disaster & $\begin{array}{l}\text { According to the impact of coal mining subsidence, it is divided into } 1 \\
\text { - } 4 \text { levels }\end{array}$ & + & 0.0666 & 0.4453 \\
\hline \multirow[t]{2}{*}{ Livability } & $\begin{array}{l}\text { Ecological } \\
\text { vulnerability }\end{array}$ & $\begin{array}{l}\text { The potential risks of water resources protection areas are divided into } \\
1-4 \text { levels }\end{array}$ & + & 0.0500 & 0.3342 \\
\hline & Construction & $\begin{array}{l}\text { There is a fixed value of } 1 \text { for the construction area of major projects, } \\
\text { and the rest are } 0\end{array}$ & - & 0.0418 & 0.2799 \\
\hline
\end{tabular}

Note: The impact levels of coal mining subsidence are serious, serious, minor, and no impact, respectively; the potential risks to water resources protection areas are high-risk areas, medium-risk areas, low-risk areas, and no impacts.

Among them, $X_{n i}$ is the standardized value of each evaluation index; $X_{i \max }$ is the maximum value in the evaluation index; $X_{i \min }$ is the minimum value in the evaluation index; $X_{i j}$ is the value of each evaluation index before standardization.

4) Calculate the score of the indicator of each rural residential area:

$$
S_{i}=X_{n i} W_{i}(i=1,2, \cdots, n)
$$

First, formulas (1) and (2) were used to determine the weight of each indicator, combined with the opinions of experts in the direction of agricultural land consolidation, to fine-tune the weights obtained, and then obtain the weights of each evaluation indicator (Table 1). Then, formulas (3) and (4) were used to calculate the scores of each evaluation index.

\section{5) Classification of rural settlements}

The clustering method of inter-group linkage system is a widely used classification method [33]. Using this classification method, rural settlements with similar evaluation index values can be classified into one category to ensure that rural settlements of the same type have similar attribute values. 


\subsection{Calculation of Potential of Rural Residential Area Consolidation}

\subsubsection{Theoretical Potential Calculation of Rural Residential Area Consolidation}

The per capita construction land standard method was adopted to determine the per capita standard construction land area as $80 \mathrm{~m}^{2} /$ person. The theoretical potential area $(\Delta S)$ is:

$$
\Delta S=S_{c u r}-B_{t} \cdot Q_{t}
$$

Among them, $S_{\text {cur }}$ is the current area of rural residential areas; $B_{t}$ is the population size; $Q_{t}$ is the standard construction land area per capita.

\subsubsection{Calculation of the Realistic Potential of Rural Residential Areas}

1) Constructing a comprehensive evaluation model of realistic potential

In the actual process of rural settlement reorganization, some influencing factors limit the conversion of theoretical potential to practical potential. Synthesize the impact of six factors at three levels: natural factors, population factors, and land use status (Table 2), quantify the influencing factors, build an evaluation model to comprehensively modify the theoretical consolidation potential [34].

Calculation formula:

$$
S^{\prime}=\Delta S \cdot K_{c o r}, K_{f i x}=\sum_{i=1}^{n}\left(X_{n i} \cdot w_{i}\right)
$$

Among them, $S^{\prime}$ is the actual potential; $\Delta S$ theoretical potential; $K_{c o r}$ is the corresponding potential correction coefficient; $n$ is the total number of indicators; $X_{n i}$ is the standardized value of each evaluation index; $w_{i}$ is the single evaluation The weight value of the indicator.

2) Index weight calculation and grading

Synthesize the importance of various restrictive factors and the size of the sample size, used the analytic hierarchy process (AHP) to obtain the weight of each evaluation index, and carried out standardization processing (formula 3,4)

\begin{tabular}{|c|c|c|c|c|}
\hline $\begin{array}{l}\text { Criterion } \\
\text { level }\end{array}$ & Indicator level & Index description & $\begin{array}{l}\text { Indicator } \\
\text { attributes }\end{array}$ & Weight \\
\hline \multirow{2}{*}{$\begin{array}{l}\text { Natural } \\
\text { factors }\end{array}$} & Terrain slope & $\begin{array}{l}\text { The slope is divided into } 5 \text { grades in sequence with } 25^{\circ}, 15^{\circ}, 6^{\circ} \text {, } \\
\text { and } 2^{\circ} \text { as the boundary }\end{array}$ & + & 0.0851 \\
\hline & Soil thickness & $\begin{array}{l}\text { Taking } 30 \mathrm{~cm}, 60 \mathrm{~cm} \text { and } 100 \mathrm{~cm} \text { as the boundary, } \\
\text { Soil thickness, divided into four levels in turn }\end{array}$ & + & 0.1007 \\
\hline \multirow{3}{*}{$\begin{array}{l}\text { Demographi } \\
\text { c factors }\end{array}$} & Urbanization rate & Urbanization rate of local townships & + & 0.2082 \\
\hline & $\begin{array}{l}\text { Proportion of young and } \\
\text { middle-aged population }\end{array}$ & Proportion of population aged 18 - 50 in local townships & - & 0.0843 \\
\hline & $\begin{array}{l}\text { Proportion of employees in } \\
\text { secondary and tertiary industries }\end{array}$ & $\begin{array}{l}\text { Proportion of population engaged in secondary and tertiary } \\
\text { industries in local townships }\end{array}$ & + & 0.1083 \\
\hline \multirow{2}{*}{$\begin{array}{l}\text { Land use } \\
\text { status }\end{array}$} & Intensity of settlements & Intensive degree of patches in various rural residential areas & + & 0.1279 \\
\hline & Farm-to-civil ratio & Area of cultivated land/area of residential area & - & 0.2855 \\
\hline
\end{tabular}

Table 2. Evaluation index of realistic potential of rural residential renovation. 
and assign values. Finally, according to (Equation (8)), the correction coefficient and the actual consolidation potential of rural residential areas were calculated. Using the classification method of natural discontinuities, the consolidation potential of rural residential areas in Feicheng City was divided into 4 levels in terms of townships [35].

\section{Results}

\subsection{Classification of Rural Settlements}

The study combined the land and space planning of Feicheng and the special plan for historical and cultural protection, determined the boundaries of urban development and the scope of characteristic protected villages, and screened out 148 urban-rural integration types and 41 characteristic protection types. For rural residential areas without special requirements, 12 evaluation indicators were selected from the four aspects of resource endowment, economy and society, supporting facilities and livability, to construct a classification and evaluation system for rural residential areas, and divided them into 56 cluster developing village, 155 keeping and limiting village and 221 relocating and merger village (Table 3). A total of 621 rural settlements of various types were involved, with a total scale of $6333.22 \mathrm{hm}^{2}$, covering 14 towns in the city, and the proportions and spatial distribution were basically in line with the actual situation (Figure 2).

Table 3. Classification results of rural settlements.

\begin{tabular}{cccccccc}
\hline Township & URIV & HCV & CDV & KLV & RMV & $\begin{array}{c}\text { Population } \\
\text { size }\end{array}$ & $\begin{array}{c}\text { Area of } \\
\text { village } / \mathbf{h m}^{2}\end{array}$ \\
\hline Xincheng Street & 22 & 0 & 0 & 1 & 3 & 0.26 & 38.84 \\
Laocheng Street & 35 & 6 & 1 & 3 & 2 & 2.89 & 118.31 \\
Shiheng Town & 14 & 1 & 10 & 16 & 2 & 2.82 & 444.69 \\
Hutun Town & 6 & 5 & 4 & 10 & 21 & 3.69 & 378.71 \\
Wang Guadian Street & 21 & 2 & 2 & 4 & 5 & 1.88 & 147.85 \\
Taoyuan Town & 4 & 1 & 6 & 13 & 18 & 4.59 & 644.48 \\
Bianyuan Town & 9 & 6 & 5 & 39 & 21 & 6.92 & 783.97 \\
Anjiazhuang Town & 3 & 3 & 4 & 15 & 46 & 5.36 & 915.87 \\
Wenyang Town & 9 & 8 & 3 & 21 & 13 & 5.39 & 621.94 \\
Chaoquan Town & 2 & 0 & 3 & 5 & 1 & 1.03 & 272.61 \\
Wangzhuang Town & 4 & 3 & 9 & 10 & 27 & 4.14 & 745.13 \\
Anlinzhan Town & 5 & 2 & 4 & 7 & 30 & 4.5 & 549.44 \\
Sunbo Town & 2 & 1 & 4 & 3 & 7 & 1.98 & 319.86 \\
Yiyang Street & 12 & 3 & 1 & 8 & 25 & 3.57 & 351.54 \\
Total & 148 & 41 & 56 & 155 & 221 & 49.02 & 6333.22 \\
\hline
\end{tabular}

Note: "Others" refers to the management scope of the state-owned forest farm and Tai' an Water Resources Bureau, which are not covered in this study area. 


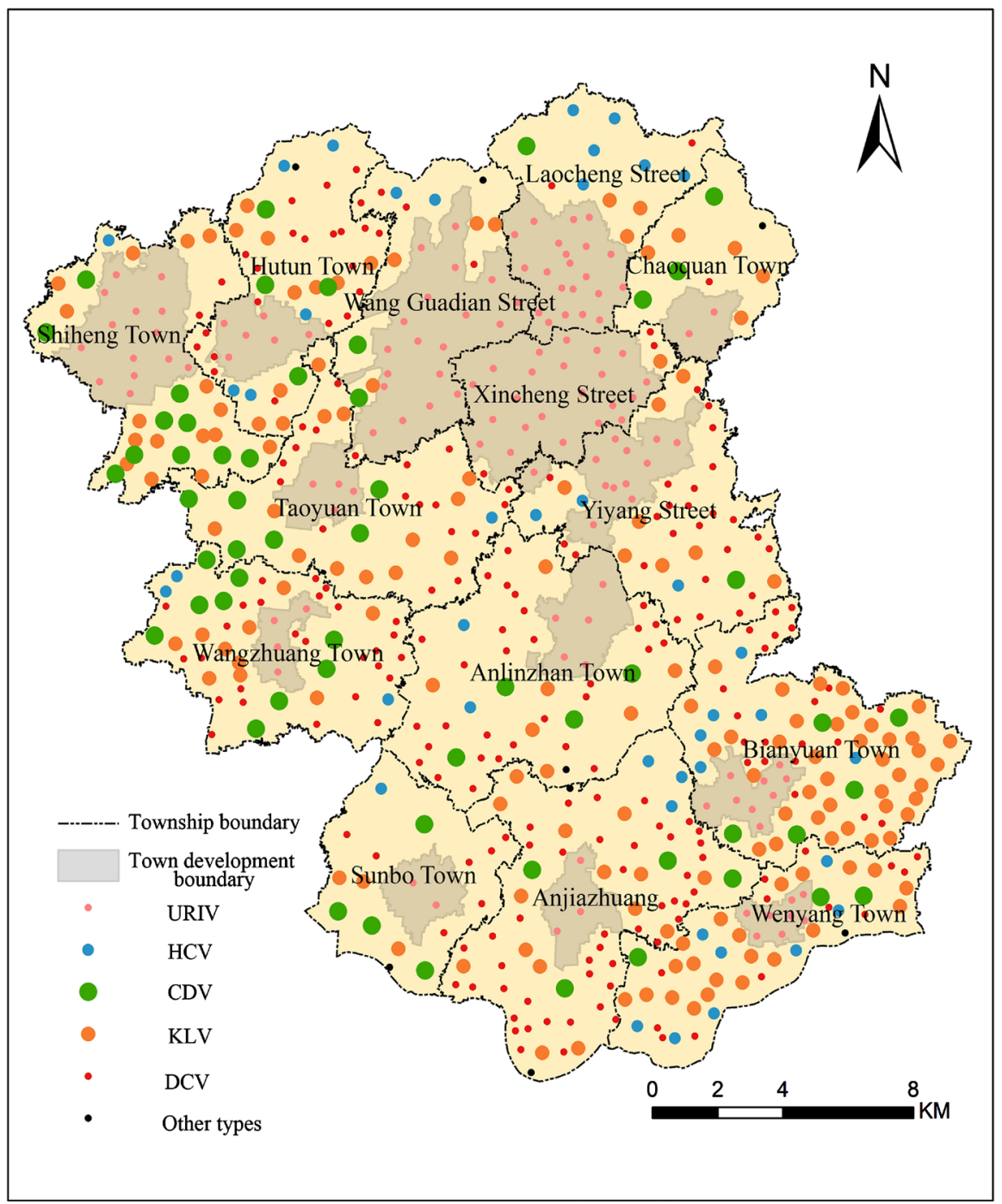

Figure 2. Classification spatial distribution map of rural residential areas in Feicheng.

Urban-rural integration village (URIV): This type of rural settlements was mainly covered by the main urban areas of counties and cities, towns and suburbs, with a total of 148 rural settlements, accounting for $23.83 \%$ of the total. The rural settlements within the coverage of the urban development boundary were mainly distributed around cities and towns. As a whole, the coverage of the northern region was wider than that of the southern region, and the urban development boundary of the four sub-districts in the northeastern region was connected together, which was the largest Area.

Historical and cultural village (HCV): mainly villages with special protection value, a total of 41 villages, accounting for $6.6 \%$. The direction of its reorganization was to coordinate the relationship between protection, utilization and development, combine characteristic resources with cultural tourism and leisure industries, and drive local development.

Cluster developing village (CDV): This type of rural settlement was characterized by superior resource endowment conditions, large and concentrated settle- 
ments, and relatively completes agricultural production and living facilities. A total of 56 rural settlements, accounting for $9.02 \%$, were rural revitalization. In terms of spatial distribution, there were more rural settlements of this type in the northern region than in the southern region. The reason was that the financial situation of the northern townships was better than that of the southern region, and can support the retention and development of more rural settlements under the same conditions. At the junction of Wangzhuang Town, Taoyuan Town and Shiheng Town, the density of agglomerated and developed rural settlements was relatively high. The main urban agglomeration in the east could be used to develop industrial clusters in rural areas and form a new pattern of coordinated development of urban and rural areas.

Keeping and limiting village (KLV): Compared with agglomeration development type rural settlements, the development conditions of this type of rural settlements were outstanding. A total of 155 rural residential areas accounts for $24.96 \%$. The future development direction was to maintain the status quo of residential areas, improved the production and living environment, and improved the quality of life of the people. In terms of spatial distribution, the remaining rural residential areas were mainly distributed in the areas surrounding the development boundaries of towns and towns. Among them, the southern part of Feicheng City, especially Bianyuan Town and Wenyang Town, were more concentrated, mainly because this area was a traditional agricultural production area. This feature could be combined to vigorously develop modern agriculture and improve the vitality of residential development.

Relocating and merger village (RMV): This type of rural residential area had shortcomings in its own resource endowment conditions, and the production and living conditions cannot meet the needs of local rural residents. Due to the fragmented patches of rural residential areas and the limited scale of funds and technical support, the benefits of infrastructure construction and industrial upgrading in such villages were not significant. Therefore, it was a more rational choice to rationally invest limited resources in areas with high development potential. There were a total of 221 such rural settlements, accounting for $35.59 \%$ of the total, which was the largest number among the five types. In terms of spatial distribution characteristics, the relocation and merged rural settlements of various towns and villages were mainly distributed in the fringe areas of towns and towns, far away from the urban area, and it was difficult to cover infrastructure and public services. In the northern part of Feicheng, some relocating and merger village areas are located in the coal mining subsidence area, and the risk of geological disasters was higher; the central area was within the scope of the water resources protection zone and the ecological environment was fragile; on the whole, Feicheng There were more Relocating and merger in the southern part of the city than in the northern part, of which 46were involved in An Jiazhuang Town.

\subsection{Analysis of the Potential Scale of Relocating and Merger Village}

Different types of rural settlements had different development directions. Rural 
settlements had completed the entire process of relocation, construction and demolition. Only the rural settlements that had been scientifically planned and constructed could truly release their consolidation potential, and different rural settlements of the same type were due to natural conditions, demographic factors, and land. There were differences in conditions such as utilization status, and the actual potential of its used value will also be different. In order to make the research results have practical application value, this research focused on calculating the theoretical and practical potentials of relocation and merger-type rural settlements relocating and merger village with higher reorganization potential (Table 4 and Figure 3).

Due to the influence of the size of their own settlements, population and other factors, the theoretical potential, practical potential and comprehensive correction coefficients of rural settlements of various towns and villages showed large differences. The total theoretical potential scale of Feicheng relocating and merger village was $1971.47 \mathrm{hm}^{2}$, accounting for $19.52 \%$ of the total scale of Feicheng rural settlements. Among them, Anjiazhuang Town involves the most rural residential areas and has the highest theoretical potential. It was the only first-level potential area, reaching $544.09 \mathrm{hm}^{2}$. The total scale of the actual potential for relocating and merger village was $1082.68 \mathrm{hm}^{2}$, accounting for $54.92 \%$ of the theoretical potential. Due to the large theoretical potential base of Anjiazhuang Town, even though it was restricted by factors such as the level of urbanization

Table 4. The theoretical and realistic potential of rural settlement readjustment in Feicheng.

\begin{tabular}{|c|c|c|c|c|c|}
\hline Township & $\begin{array}{l}\text { Theoretical } \\
\text { potential } / \mathrm{hm}^{2}\end{array}$ & $\begin{array}{l}\text { Potential } \\
\text { grading }\end{array}$ & $\begin{array}{c}\text { Realistic } \\
\text { potential } / \mathrm{hm}^{2}\end{array}$ & $\begin{array}{c}\text { Potential } \\
\text { grading }\end{array}$ & $\begin{array}{l}\text { Comprehensive } \\
\text { correction } \\
\text { factor }\end{array}$ \\
\hline Xincheng Street & 42.11 & Level 4 & 39.30 & Level 4 & 0.6705 \\
\hline Laocheng Street & 29.44 & Level 4 & 17.36 & Level 4 & 0.5895 \\
\hline Shiheng Town & 17.11 & Level 4 & 12.06 & Level 4 & 0.7048 \\
\hline Hutun Town & 102.49 & Level 3 & 63.06 & Level 3 & 0.6153 \\
\hline Wang Guadian Street & 42.17 & Level 4 & 29.83 & Level 4 & 0.7074 \\
\hline Taoyuan Town & 149.56 & Level 2 & 73.87 & Level 3 & 0.4939 \\
\hline Bianyuan Town & 141.37 & Level 2 & 69.35 & Level 3 & 0.4906 \\
\hline Anjiazhuang Town & 544.09 & Level 1 & 318.10 & Level 1 & 0.5846 \\
\hline Wenyang Town & 174.82 & Level 2 & 93.57 & Level 2 & 0.5352 \\
\hline Chaoquan Town & 32.45 & Level 4 & 20.43 & Level 4 & 0.6294 \\
\hline Wangzhuang Town & 241.66 & Level 2 & 121.13 & Level 2 & 0.5012 \\
\hline Anlinzhan Town & 182.73 & Level 2 & 96.75 & Level 2 & 0.5295 \\
\hline Sunbo Town & 69.90 & Level 3 & 42.92 & Level 3 & 0.6140 \\
\hline Yiyang Street & 201.57 & Level 2 & 96.02 & Level 2 & 0.4764 \\
\hline Total & 1971.47 & & 1082.68 & & \\
\hline
\end{tabular}




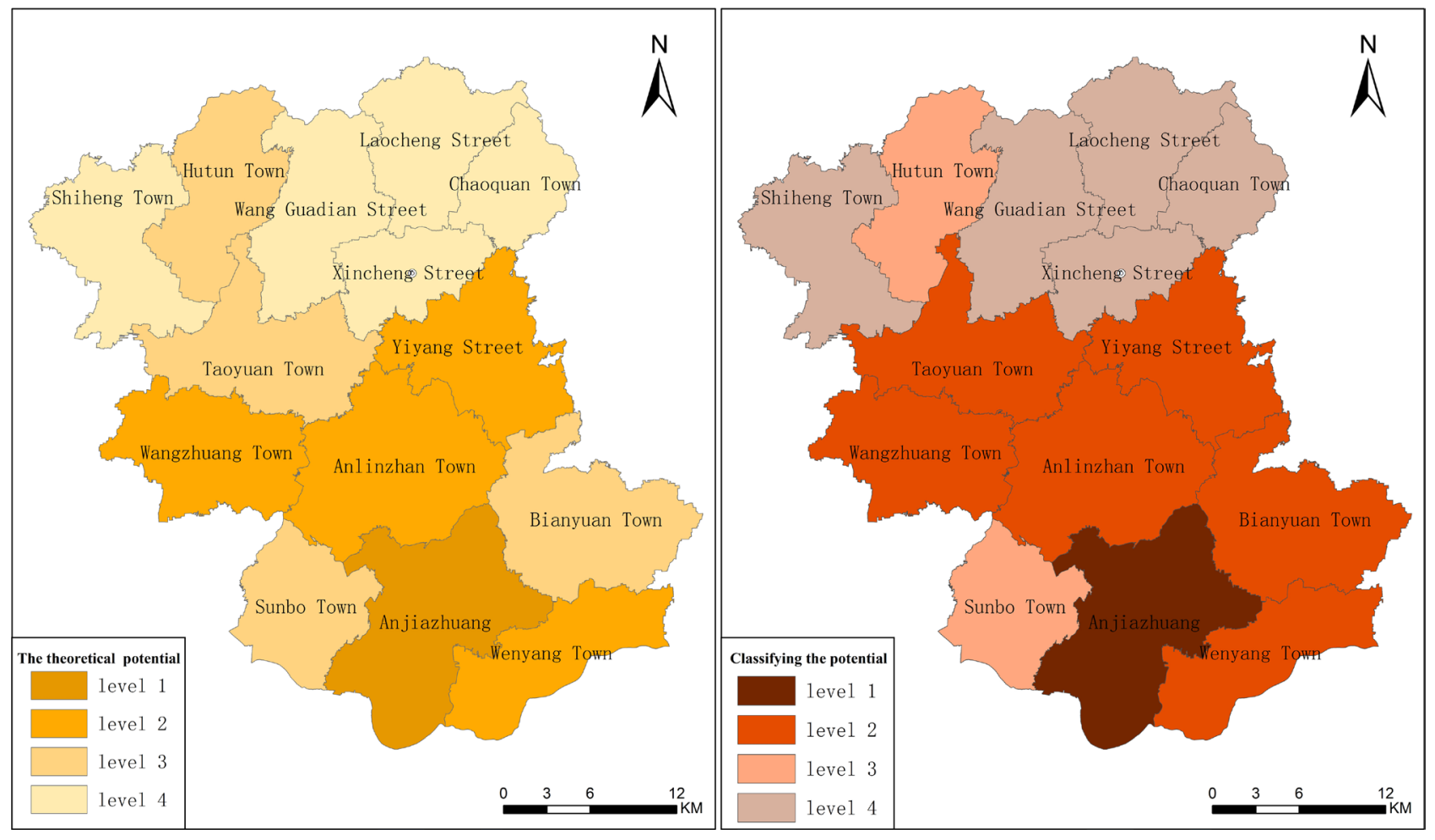

Figure 3. Classifying the potential value of rural settlement readjustment in Feicheng.

and human-land contradictions, the comprehensive correction coefficient of the town is only 0.5846 , and its actual potential scale was also the largest. This area had low cost, high efficiency, and quick results. It could be used as a key area for reorganization. However, Shiheng Town and Wangguadian Streets were less restrictive to potential transformation, so the comprehensive correction coefficients are 0.7048 and 0.7074 respectively, which were at a relatively high level. The urbanization rate of Yiyang Street was only 0.21 , and the contradiction between people and land wasmore prominent, so the comprehensive correction coefficient was the lowest, and the potential conversion efficiency was low.

\subsection{Analysis of Spatial Distribution and Change of Sorting Potential}

In terms of spatial distribution, both theoretical and actual potentials showed that the northern region was significantly lower than the central and southern regions. The main reasonwas that the northern region's own resource endowment and economic and social development were generally better than the central and southern regions, and the relocating and merger village involved The number of sites was small, and the scale of reorganization is relatively small. Moreover, the central and southern regions were traditional agricultural agricultural areas with dense populations and large-scale rural settlements, so the efficiency of rural settlement reorganization was relatively high. With Anlinzhan Town as the center, high-potential areas were concentrated, forming a key consolidation area in the south. In the northern region, around the main urban area of Feicheng, a 


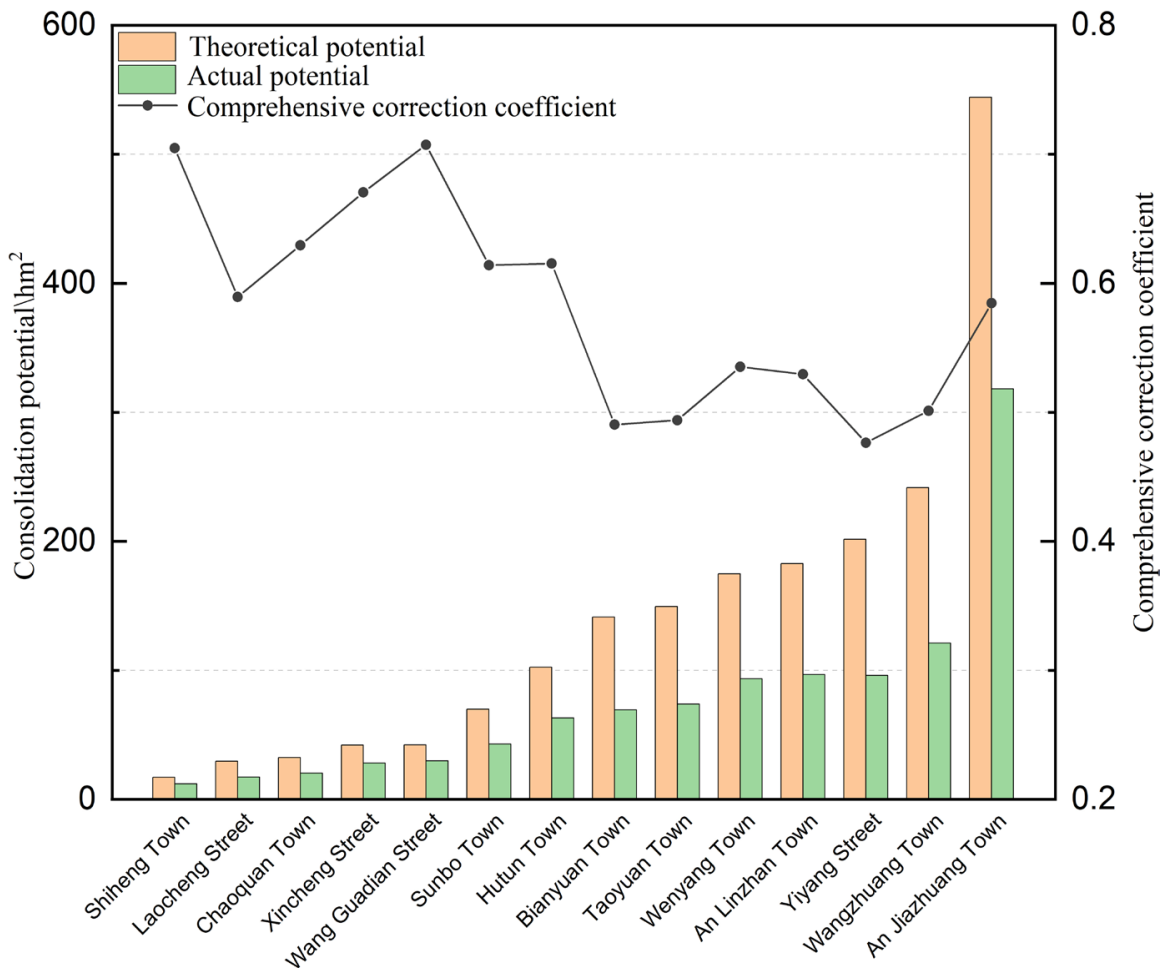

Figure 4. Changes in the potential for remediation of rural residential areas.

low-potential reorganization area in the northern region was formed, which involved fewer rural settlements and relatively little resistance to reorganization. In terms of potential changes (Figure 3 and Figure 4), the five towns of Shiheng Town, Laocheng Street, Chaoquan Town, Xincheng Street and Wangguadian Street were restricted by their own remediation scales, and their comprehensive correction coefficients were relatively high. Therefore, their potential changes were relatively small; the other 9 towns had more obvious changes in their potential values, especially Anjiazhuang Township's potential value changes by $225.9 \mathrm{hm}^{2}$. The potential levels of most towns and villages did not change significantly before and after the revision. Only the potential levels of Taoyuan Town and Bianyuan Township were reduced from Level 2 to Level 3, indicating that their potential conversion efficiency was low.

\section{Discussion}

At present, agricultural and rural modernization is progressing steadily, and land consolidation in rural areas has gradually become one of the hot topics of discussion and research. Rural settlement consolidation is an indispensable link in land consolidation. It is in the promotion of people-oriented new urbanization and in-depth promotion of rural revitalization strategies. There is an important meaning in this respect. According to the scientific classification of rural residential areas according to the law of development and evolution, and quantitatively describe the potential of rural residential areas consolidation, land consolidation planning can be formulated in accordance with regional characteristics 
and inject new impetus into local development. This study uses the above research methods to divide Feicheng's rural residential areas into five types. The proportion and spatial distribution of each type of rural residential areas are relatively uniform and basically consistent with the actual situation. In the process of calculating the realistic potential of the selected relocating and merger village, the multi-factor comprehensive correction method is adopted, and representative factors can be selected to truly reflect the basic conditions of different rural settlements, and the final calculated theory, realistic potential and the comprehensive correction coefficient is in line with the actual situation as a whole. The main purpose of carrying out rural settlement reorganization is to promote rural revitalization, and the economic and social benefits it produces are indispensable resources for the development of agriculture, rural areas, and farmers [36]. Therefore, in the process of classifying rural settlements and calculating the potential for consolidation, the starting point is to protect the interests of farmers and increase their land income. How to comprehensively consider the "human" factors of relevant farmer groups and include them in the evaluation system requires further research.

\section{Conclusions}

1) Combining the corresponding planning, this study established a classification and evaluation system for rural residential areas and divided the 621 rural residential areas in Feicheng into 148 urban-rural integration villages, 41 historical and cultural villages, 56 cluster developing villages, 155 keeping and limiting villages and 221 relocating and merger villages (RMV). The proportions of various types of rural residential areas were coordinated, and the spatial layout is more reasonable. It not only implemented the relevant requirements of land and space planning and characteristic protection but also reflected the differences of different types of rural residential areas, so as to better identify relocating and merger village.

2) The relocating and merger village were the key areas for rural settlement consolidation. By using the per capita construction land standard method, the theoretical potential of rural settlement consolidation within the research area was calculated to be $1971.47 \mathrm{hm}^{2}$, accounting for the total scale of urban settlements. 19.52\%; A comprehensive evaluation model of realistic potential was constructed, and the comprehensive correction coefficient of each area was calculated to be $0.48-0.70$. The practical potential of rural residential settlements was $1082.68 \mathrm{hm}^{2}$, accounting for $54.92 \%$ of the theoretical potential. There were big differences in the scale and space of consolidation potential in different regions. In general, the theoretical and practical potential of the central and southern regions was higher than that of the northern regions.

Using the method of first classifying and then calculating and reorganizing potential, it can reasonably screen out the relocating and merger village, quantify the impact of restrictive factors on potential transformation, accurately calcu- 
lated the actual potential, and prepared corresponding plans and carried out differentiated rural residential area reorganization.

\section{Acknowledgements}

This research was supported by the National Key Research and Development Program of China (2017YFE0122500); the Major Science and Technology Innovation Project of Shandong Province (2018CXGC0209); Shandong Taishan Scholars Climbing Program; Shandong Province "Double First Class" Funding Project (SYL2017XTTD02).

\section{Conflicts of Interest}

The authors declare no conflicts of interest regarding the publication of this paper.

\section{References}

[1] Zhang, K.F., Li, X.W., Zhang, D.X., et al. (2006) Spatial-Temporal Dynamic Change of Land Resource Degradation in China. Environmental Science, No. 6, 1244-1251.

[2] Li, Y.R., Liu, Y.S. and Long, H.L. (2010) Spatio-Temporal Analysis of Population and Residential Land Change in Rural China. Journal of Natural Resources, 25, 1629-1638.

[3] Hosseini, S.B., Faizi, M., Norouzian-Maleki, S., et al. (2015) Impact Evaluation of Rural Development Plans for Renovating and Retrofitting of Rural Settlements. Environmental Earth Sciences, 73, 3033-3042. https://doi.org/10.1007/s12665-011-1403-3

[4] Jerzy Bański, B.M.W. (2010) Transformations in Housing Construction in Rural Areas of Poland's Lublin Region Influence on the Spatial Settlement Structure and Landscape Aesthetics. Landscape and Urban Planning, 94, 116-126. https://doi.org/10.1016/j.landurbplan.2009.08.005

[5] Porta, J., Parapar, J., Doallo, R., et al. (2013) A Population-Based Iterated Greedy Algorithm for the Delimitation and Zoning of Rural Settlements. Computers, Environment and Urban Systems, 39, 12-26. https://doi.org/10.1016/j.compenvurbsys.2013.01.006

[6] Gao, Y. (2004) Suitability Evaluation and Model and Policies of Rural Residential Land Readjustment. Zhejiang University, Hangzhou.

[7] Kong, X.S., Liu, Y.L., Deng, X.K., et al. (2012) Suitability Evaluation and Consolidation Division of Rural Residential Areas in Villages and Towns. Transactions of the Chinese Society of Agricultural Engineering, 28, 215-222+293.

[8] Zhu, S.C. (2018) Study on the Evolution and Spatial Optimization of Rural Residential Land-Take Jiashan as an Example. Zhejiang University, Hangzhou.

[9] Shao, S.Y. and Li, J.L. (2018) Studying the Changes and Characteristics of Landscape Patterns Involving Rural Residents in the Simingshan Area. Shanghai Land \& Resources, 39, 27-33.

[10] Zou, L.L. and Wang, J.Y. (2015) Review of Research on Layout Optimization of Rural Settlements in China. China Population, Resources and Environment, 25, 59-68.

[11] Tan, X.L., Duan, J.N., Bao, C.H., et al. (2010) A GIS-Based Study on Optimized Spatial Distribution of Rural Settlements in Mayang County. Research of Soil and Wa- 
ter Conservation, 17, 177-180+185.

[12] Ni, L., Song, A.A., Zheng, Y.D., et al. (2019) Study on the Zoning of Rural Residences of Space in Mountains Based on Ecological Constraints-A Case Study in Laiyuan County of Hebei. Chinese Journal of Agricultural Resources and Regional Planning, 40, 26-33.

[13] Luo, Z.J., Zhao, Y., Li, Y.T., et al. (2019) Research on Rural Residential Area Layout Optimization Based on Spatial Combination Characteristics. Transactions of the Chinese Society of Agricultural Engineering, 35, 265-272+314.

[14] Huang, C., Zhao, X.M., Guo, X., et al. (2016) Study on the Rural Residential Layout Optimization of Yujiang County Based on Kernel Density. Journal of China Agricultural University, 21, 165-174.

[15] Liu, S.K., Wei, S.Q., Chen, S.L., et al. (2014) Voronoi Diagram-Based Research on Spatial Distribution Characteristics of Rural Settlements and Consolidation Potential Evaluation. Resources Science, 36, 2282-2290.

[16] Zhang, Y. and Xu, H. (2014) Research on Suitability Subareas of Rural Residential Distribution Based on MCR Model and Optimization Model-A Case Study of Jin Niuhu Street in Nanjing, Luhe District. Resources and Environment in the Yangtze Basin, 23, 1485-1492.

[17] Liu, Y.F., Yang, Q.Y., Liao, H.P., et al. (2004) A Study of the Calculation Methods for the Potential of Rural Residential Point Re-Arrangement in the Hilly Regions of Southwest China-A Case Study of Yubei District, Chongqing. Journal of Teacher Education, No. 4, 11-14.

[18] Chen, Z.A., Zhang, L.T., Zeng, L.Q., et al. (2011) Analyzing of Intensive Land Use Appraise and Potential Calculation in Rural Residential Areas-Taking Typical Village in Dongxiang City as an Example. Guangdong Agricultural Sciences, 38, 146$147+160$.

[19] Jia, M. (1999) Connotation Tapping Potential, Returning Homes to Fields-Analysis of the Land Consolidation Potential of Rural Residential Areas in Jilin Province. Agriculture of Jilin, No. 9, 2-3.

[20] Li, H., Liu, X.G. and Su, A.Y. (2007) Investigate on Rural Residential Land and Land Readjustment Potential Forecast in Heilongjiang Province. Territory \& Natural Resources Study, No. 2, 47-48.

[21] Ma, Z.H., Wen, Z.J. and Zhang, T. (2007) A Study of Rural Residential Land Scale Calculations in Land Use Planning-With Land Use Planning of Hunan as an Example. Scientific and Technological Management of Land and Resources, No. 2, 76-80.

[22] Shi, S.Y. and Zhang, X.L. (2009) Current Situation Analysis and Land Reconsolidation Potential Calculation of Rural Residential Areas in Jiangsu Province. China Land Science, 23, 52-58. https://doi.org/10.1007/s11431-008-0276-5

[23] Qu, Y.B., Zhang, F.R., Song, W., et al. (2012) Integrated Correction and Calculation of Rural Residential Consolidation Potential: A Case Study of Pinggu District, Beijing. Acta Geographica Sinica, 67, 490-503.

[24] Sun, J.W., Luo, J., Kong, X.S., et al. (2017) Zoning and Potential Calculation for Rural Settlements Consolidation in Qinba Mountainous Area Based on Spatial Characteristics. Human Geography, 32, 80-87+94.

[25] Yang, W.W. and Wang, Y.P. (2017) Comparison Analysis on Calculation Method of Land Arrangement Potential in Rural Residential Areas. Hubei Agricultural Sciences, 56, 3941-3946. 
[26] Sa, L.W., Sun, Y.P. and Gu, N. (2019) Comprehensive Evaluate of Rural Residential Land Consolidation Potential of Loess Plateau Based on GIS. Journal of Xí an University of Architecture \& Technology (Natural Science Edition), 51, 396-402+410.

[27] Yan, D.H. (2004) The Method and Practice of Calculating the Potential of Rural Land Rehabilitation. China Agricultural University, Beijing.

[28] Zhu, X.H., Chen, Y.F., Liu, Y.S., et al. (2010) Technique and Method of Rural Land Consolidation Potential Investigation and Assessment: A Case Study of Yucheng City, Shandong Province. Acta Geographica Sinica, 65, 736-744.

[29] Ni, J.P., Li, P., Wei, C.F., et al. (2009) Potentialities Evaluation of Regional Land Consolidation Based on AHP and Entropy Weight Method. Transactions of the Chinese Society of Agricultural Engineering, 25, 202-209.

[30] Kong, X.S., Liu, Y.F., Zou, Y.F., et al. (2010) Calculation of Land Consolidation Potential and Optimization of Rural Residential Areas Based on Households' Willingness. Transactions of the Chinese Society of Agricultural Engineering, 26, 296-301.

[31] Zhou, Y., Li, Y. and Xu, C. (2020) Land Consolidation and Rural Revitalization in China: Mechanisms and Paths. Land Use Policy, 91, Article ID: 104379.

https://doi.org/10.1016/j.landusepol.2019.104379

[32] Ma, Y.X., Liu, X.L. and Huang, J.Z. (2010) The Influence of Land Evaluation Methods on Index Weights-Taking Yongdeng County and Gaolan County of Lanzhou City as Examples. Hunan Agricultural Sciences, No. 8, 32-34+39.

[33] Zhao, R.Q., Huang, X.J., Zhong, T.Y., et al. (2010) Application of Clustering Analysis to Land Use Zoning of Coastal Region in Jiangsu Province. Transactions of the Chinese Society of Agricultural Engineering, 26, 310-314.

[34] Zhang, K.X. (2019) Research on Rural Residential Lands Consolidation in Luopu County. Xinjiang University, Uyghur.

[35] Zhu, T.F., Zhang, F.R., Li, C., et al. (2015) Evaluation on Intensive Use of Rural Residential Land: A Case Study of Mentougou District in Beijing City. Areal Research and Development, 34, 160-165.

[36] Liu, Y.H. and Chen, W.Q. (2014) Calculation of Land Consolidation Potential Based on GIS. Applied Mechanics and Materials, 580-583, 2769-2773. 